\title{
Pelatihan Penggunaan Sistem Informasi Pengelolaan Surat Keluar di Desa Dunggala Kecamatan Tapa Kabupaten Bone Bolango
}

\author{
Wrastawa Ridwan dan Rahmat D. R. Dako \\ Prodi Teknik Elektro, Universitas Negeri Gorontalo, Jl. Jend. Sudirman no.6, Kota Gorontalo 96128 \\ E-mail: wridwan@ung.ac.id
}

\begin{abstract}
Abstrak - Penilaian kinerja pemerintahan yang baik ditandai dengan kualitas pelayanannya terhadap masyarakat. Salah satu peran desa sebagai pengelola administrasi pemerintahan terendah dalam sebuah daerah adalah melayani masyarakatnya dalam pembuatan surat. Pengelolaan surat keluar di Desa Dunggala Kecamatan Tapa Kabupaten Bone Bolango Provinsi Gorontalo masih dilakukan secara konvensional, yaitu dengan mencatat nomor surat pada buku agenda. Hal ini mengakibatkan petugas desa mengalami kesulitan dalam pengelolaan arsip persuratan apabila di kemudian hari diperlukan surat dengan nomor tertentu. Kegiatan pengabdian kepada masyarakat ini bertujuan membantu pemerintah desa dalam mengelola surat keluar dengan merancang sistem informasi pengelolaan surat keluar. Sistem informasi yang dibangun berbasis aplikasi web namun pada penerapannya masih digunakan secara offline atau localhost, karena kendala jaringan internet di kantor desa. Sistem database digunakan untuk penyimpanan data agar mudah dalam pencarian surat yang telah dibuat. Selanjutnya, petugas desa dilatih untuk menggunakan sistem informasi ini. Hasil yang diperoleh dari kegiatan ini adalah adanya sistem informasi pengelolaan surat keluar dan terlatihnya petugas desa dalam menggunakan sistem tersebut. Sistem informasi ini dapat dikembangan lebih lanjut dengan memperhatikan kebutuhan yang ada di desa.
\end{abstract}

Kata Kunci — sistem informasi, surat keluar, desa dunggala

\begin{abstract}
Assessment of good government performance is characterized by the quality of its services to the community. One of the roles of the village as the lowest administrative level in a region is to serve the community in making letters. Management of outgoing mail in Desa Dunggala, Kecamatan Tapa, Kabupaten Bone Bolango is still done conventionally, namely by recording the letter number in the agenda book. This resulted in village officials experiencing difficulties in managing the correspondence archives if in the future a letter with a certain number was needed. This community service activities aimed at helping the village government in managing outgoing mail by designing information system for managing outgoing mail. The information system was built based on the web application, but in its application is still used offline or localhost, due to internet network constraints in the village office. A database system is used for data storage so that it is easy to search the letters that have been made. Then, the village officials has been trained to use the information system. The results obtained from this activity are the information system for managing outgoing mail and the training of village officials in using the application. This information system can be further developed by taking into account the needs that exist in the village.
\end{abstract}

Keywords — information system, outgoing mail, desa dunggala

\section{Pendahuluan}

Pemerintahan Desa adalah penyelenggaraan urusan pemerintahan dan kepentingan masyarakat setempat dalam sistem pemerintahan Negara Kesatuan Republik Indonesia [1]. Berdasarkan UU No. 6 Tahun 2014 tentang Desa, dalam pasal 4 butir f dinyatakan bahwa Pengaturan Desa bertujuan meningkatkan pelayanan publik bagi warga masyarakat desa guna mempercepat perwujudan kesejahteraan umum. Salah satu item dalam pelayanan publik kepada masyarakat desa yaitu melayani masyarakat dalam hal pembuatan surat. Pengelolaan surat-surat ini jika tidak dilakukan dengan tepat dan efisien maka akan mengurangi penilaian masyarakat terhadap kinerja pemerintah yang seharusnya memberikan pelayanan secara prima. Standar pelayanan adalah tolak ukur yang dipergunakan sebagai pedoman penyelenggaraan pelayanan dan acuan penilaian kualitas pelayanan sebagai kewajiban dan janji penyelenggara kepada masyarakat dalam rangka pelayanan yang berkualitas, cepat, mudah, terjangkau, dan teratur [2]. Berdasarkan survey awal yang dilakukan di Kantor Desa Dunggala Kecamatan Tapa Kabupaten Bone Bolango Provinsi Gorontalo, mekanisme pengurusan surat masih dilakukan secara konvensional, walaupun sudah menggunakan perangkat komputer. Penggunaan komputer hanya merupakan pemutakhiran perangkat dari mesin ketik biasa, 
tanpa memaksimalkan kemampuan komputer sebagai perangkat yang mutakhir. Komputer hanya sebagai pengganti mesin ketik untuk mencetak surat. Selanjutnya, dalam hal pengelolaan surat, misalnya menyangkut nomor surat, dilakukan dengan mencatat pada buku agenda. Demikian pula, arsip surat yang telah dicetak tidak memiliki penataan pengarsipan yang baik. Misalnya jika diperlukan surat keluar dengan nomor tertentu, pelacakannya dilakukan dengan memeriksa kembali arsip-arsip surat di dalam bundelan. Di sisi lain, file surat tersebut di komputer sudah tidak ada lagi. Berdasarkan hal ini perlu adanya pemberdayaan sumber daya manusia perangkat desa dalam mengelola surat keluar berbasis sistem informasi.

\section{ANALISIS SITUASI}

Mitra dalam kegiatan PKM ini adalah Desa Dunggala Kecamatan Tapa Kabupaten Bone Bolango. Dalam upaya untuk mengatasi permasalahan-permasalahan dalam pengelolaan surat yang telah dikemukakan di atas, dapat dilakukan dengan pelatihan berbasis komputer bagi perangkat desa untuk membuat sebuah pengelolaan secara terpadu dalam hal penomoran dan pengarsipan surat keluar. Dalam pelatihan ini suratsurat keluar disimpan ke dalam perangkat penyimpanan komputer dengan pengenal atau nama filenya adalah nomor dari surat tersebut. Hal ini dilakukan agar tidak terjadi duplikasi nomor surat. Surat-surat yang keluar ini pun harus dikelompokkan ke dalam kelompok jenis surat agar mudah untuk pencarian kembali. Proses pencarian dilakukan dengan cukup memasukkan nomor surat atau memilih jenis suratnya.

Manajemen pengelolaan surat mulai dari pengisian biodata, keperluan pembuatan surat surat, penamaan file surat, lokasi penyimpanan ke dalam perangkat penyimpanan (penataan folder), pencarian kembali surat dapat dilakukan secara terpisah. Namun hal ini pun dapat menimbulkan masalah tersendiri. Masalah yang timbul apabila pengelolaan surat dilakukan secara terpisah yaitu apabila operator atau staf yang menangani hal ini lebih dari satu orang maka folder penyimpanan file tidak konsisten. Hal ini terjadi misalnya, pemberian nama file atau folder penyimpanan file dapat saja berubah karena kelalaian dari operator tersebut. Oleh karena itu, manajemen pengelolaan surat ini perlu terintegrasi secara menyeluruh baik dari pengisian biodata, keperluan pembuatan surat, penamaan file surat, penyimpanan ke dalam perangkat penyimpan, sampai pada pencarian kembali surat yang telah keluar.

Berdasarkan pertimbangan-pertimbangan yang telah dikemukakan tersebut, tim PKM mengusulkan pembuatan sistem informasi pengelolaan surat keluar serta pelatihan penggunaannya untuk penataan pengelolaan surat keluar di desa Dunggala Kecamatan Tapa Kabupaten Bone Bolango. Menurut Kadir [3], sistem informasi memberikan andil besar terhadap perubahan yang mendasar pada struktur, operasi dan manajemen organisasi. Sehingga, dengan penggunaan sistem informasi pengelolaan surat keluar ini diharapkan pelayanan desa kepada masyarakat semakin meningkat.

\section{Metode}

Sistem informasi yang dirancang ditujukan untuk melakukan otomasi administrasi seperti pada $[4,5]$. Solusi yang ditawarkan untuk menyelesaikan permasalahan yang telah dikemukakan di atas adalah dengan membuat sistem informasi pengelolaan surat keluar, serta memberikan pelatihan penggunaan sistem informasi tersebut. Sistem informasi pengelolaan surat keluar yang dirancang menerapkan skema responsif web agar sistem ini mudah diakses oleh perangkat yang memiliki ukuran layar yang berbeda. Selain itu, teknik Aynchronouse JavaScript \& XML (AJAX) digunakan agar pengaksesan sistem lebih cepat dibanding web konvensional [6-10].

Menurut Ullman dan Dykes [11], AJAX adalah sekumpulan teknik pemrograman atau suatu pendekatan secara terpisah pada pemrograman web. Teknik-teknik pemrograman ini mempengaruhi kemampuan sebuah laman web atau sebuah bagian dari laman web untuk diperbaharui dengan masukan dari server, tetapi tanpa perlu laman tersebut dimuat kembali dari awal. Secara mendasar Babin [6] mengemukakan bahwa AJAX memanfaatkan objek berbasis JavaScript XMLHttpRequest untuk melakukan permintaan kepada web server secara asinkron. Dengan menggunakan XMLHttpRequest tersebut, aplikasi web dapat mengirim informasi ke server. Sesuai permintaan tersebut, kemudian server melakukan proses. Hasil pemrosesan dari server selanjutnya mengubah bagian dari laman web secara dinamis tanpa user memindahkan atau mengubah lokasi yang sedang aktif.

\section{HASIL DAN PEMBAHASAN}

Setelah pembuatan sistem informasi pengelolaan surat keluar selesai, tahap selanjutnya adalah mengadakan pelatihan penggunaan sistem informasi ini kepada petugas Desa Dunggala Kecamatan Tapa Kabupaten Bone Bolango Provinsi Gorontalo. Kegiatan pelatihan mencakup:

- Pelatihan login pengelolaan surat keluar di kantor Desa Dunggala Kecamatan Tapa Kabupaten Bone Bolango,

- Pelatihan input biodata penduduk desa,

- Pelatihan pemilihan jenis surat yang diminta sesuai keperluan penduduk desa, 
- Pelatihan penyimpanan file surat dengan menggunakan nama sesuai nomor surat,

- Pelatihan pencetakan ke printer surat keluar

- Pelatihan pencarian data surat berdasarkan nomor atau jenis surat

Pelaksanaan kegiatan PKM ini dilakukan dalam beberapa tahap sebagai berikut,

1. Tahap Persiapan

Pada tahap ini, tim mempersiapkan kebutuhan dalam pelaksanaan kegiatan, diantaranya materi pelatihan, proyektor, laptop, dan spanduk. Ruang kegiatan menggunakan salah satu ruangan kantor desa.

2. Tahap Pelaksanaan

Kegiatan pelatihan diberikan pada aparat desa yang bertugas sebagai operator yang menangani pembuatan surat keluar.

3. Tahap Evaluasi

Di akhir pelatihan diadakan evaluasi terhadap seluruh rangkaian pelaksanaan pelatihan, yaitu dengan menguji apakah aparat desa yang dilatih telah dapat menggunakan sistem informasi pengelolaan surat keluar dengan baik.

Implementasi sistem informasi pengelolaan surat keluar di Desa Dunggala Kecamatan Tapa Kabupaten Bone Bolango 'dikemas dalam bentuk pelatihan terhadap aparat desa yang terdiri dari 6 (enam) orang yang menangani surat menyurat di lingkungan desa. Gambar 1 menunjukkan suasana pada saat pelatihan dilaksanakan. Peserta yang ikut serta dalam pelatihan dimaksud adalah aparat desa yang menangani persuratan, sebagaimana ditunjukkan pada Gambar 2. Kepala desa juga turut hadir dalam kesempatan itu.

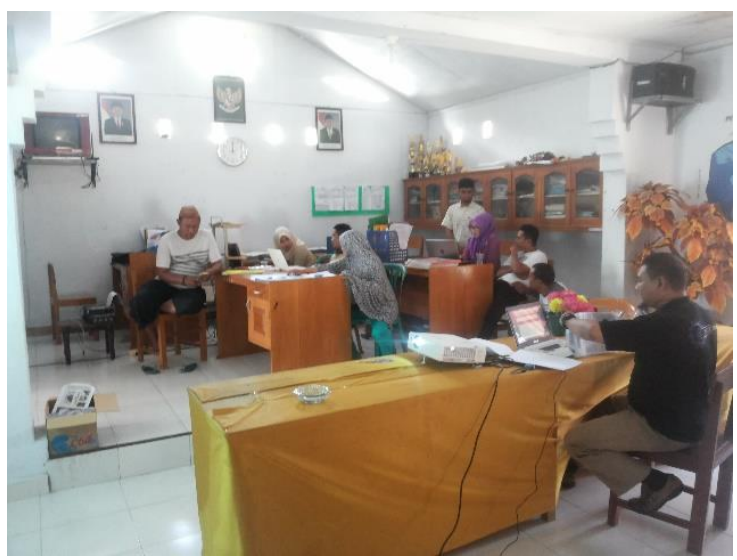

Gambar 1. Pelatihan penggunaan aplikasi komputer pengelolaan surat

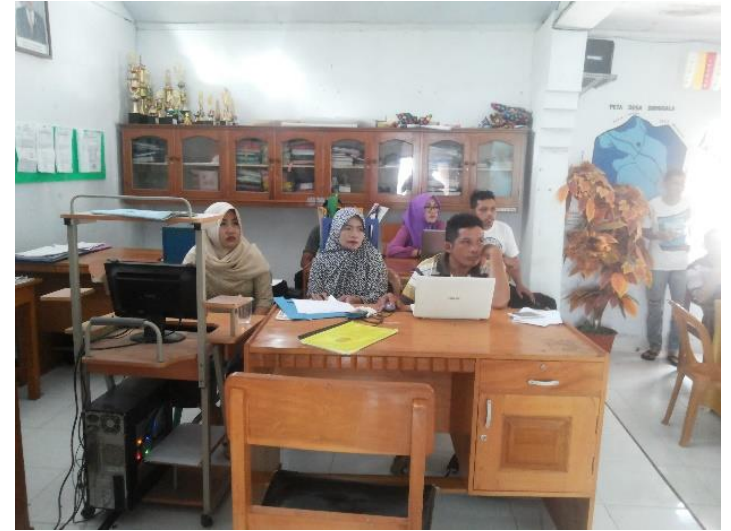

Gambar 2. Peserta pelatihan

Sebelum menggunakan sistem informasi pengelolaan surat, perlu pemasangan aplikasi pendukung pada komputer desa, yaitu:

1. Aplikasi atau software aplikasi pendukung, yaitu paket aplikasi XAMPP versi 4.2.7.1 atau versi lain yang sesuai dengan perangkat komputer pengguna [12]. Aplikasi XAMPP ini sudah terintegrasi web server Apache dan database server MySQL. Paket aplikasi ini berfungsi untuk simulasi web secara offline atau secara lokal sebelum diluncurkan menjadi online.

2. Web browser. Aplikasi yang direkomendasikan adalah Google chrome karena aplikasi ini memudahkan pengguna untuk menampilkan print preview sebelum dicetak ke mesin pencetak. Pengguna dapat menggunakan aplikasi yang lain seperti Mozilla firefox atau internet explorer.

Pelatihan diawali dengan bagaimana menggunakan sistem informasi pengelolaan surat di Desa Dunggala. Langkah pertama yang dilakukan adalah bagaimana membuka sistem informasi pengelolaan surat keluar yang dapat diakses secara offline dengan mengetikkan pada address bar :localhost/suratdg seperti yang diperlihatkan pada Gambar 3.



Gambar 3. Tampilan awal aplikasi 
Selanjutnya operator akan diminta login sistem. Jika pengguna berhasil login, maka halaman utama akan ditampilkan seperti pada Gambar 4.

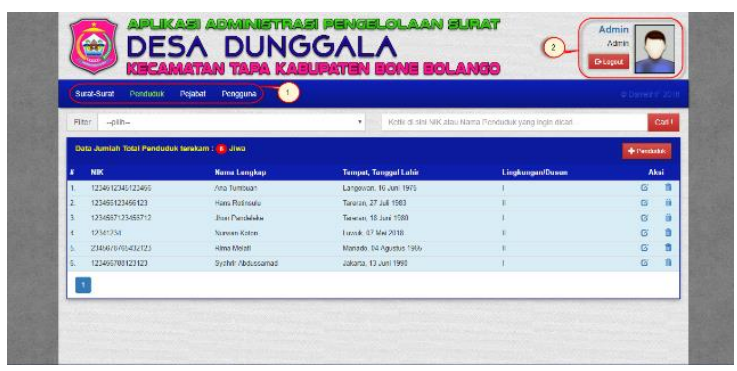

Gambar 4. Halaman utama aplikasi

Penjelasan mengenai menu utama dalam sistem informasi ini adalah sebagai berikut:

1. Tab "Surat-Surat". Tab ini berisi halaman yang menampilkan tabel-tabel surat yang tersimpan. Tabel surat yang ada dalam basis data dibagi menjadi dua tabel, yaitu tabel surat jika yang bermohon adalah penduduk tetap desa dan tabel surat yang berisi surat-surat yang diminta oleh penduduk yang berasal dari luar desa.

2. Tab "Penduduk", berisi data penduduk yang telah terdaftar.

3. Tab "Pejabat", berisi halaman untuk pejabat yang berwenang untuk menandatangani suratsurat. Pejabat-pejabat yang bisa ditambahkan pada aplikasi ini adalah camat, kepada desa dan sekretaris desa.

4. Tab "Pengguna", merupakan halaman yang berisi pengguna dari aplikasi. Tab pengguna ini hanya akan muncul jika pengguna yang login ke aplikasi adalah pengguna dengan level Admin.

5. Fitur pengguna (nomor 2 dalam Gambar 3). Fitur ini adalah infomasi data pengguna yang sedang login, yaitu nama pengguna, level pengguna (administrator atau pengguna biasa) serta tombol "Logout" untuk keluar dari sistem.

Gambar 5 menunjukkan contoh surat keluar yang dihasilkan dari sistem informasi ini. Gambar 4 merupakan surat pratinjau sebelum dicetak.

Setelah kegiatan pelatihan, dilakukan evaluasi terhadap pelaksanaan pelatihan. Hasil evaluasi diperoleh bahwa kegiatan ini sangat bermanfaat bagi peserta (staf kantor desa) dalam melakukan pelayanan kepada masyarakat, terutama pelayanan persuratan di desa. Pengelolaan surat keluar di Desa Dunggala menjadi lebih mudah dengan adanya sistem ini. Perbaikan sistem sudah dilakukan berupa penambahan jenis surat (surat kelahiran). Hal ini merupakan umpan balik saran perbaikan dari peserta pelatihan.

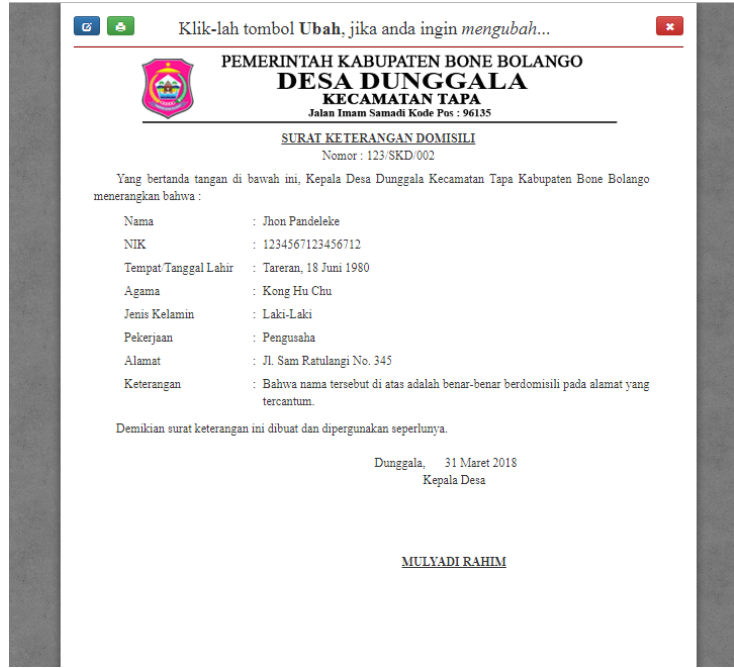

Gambar 5. Contoh surat keluar yang dihasilkan aplikasi

\section{Penutur}

Kegiatan PKM oleh tim pengabdi telah berhasil membuat sistem informasi pengelolaan surat keluar di Desa Dunggala Kecamatan Tapa Kabupaten Bone Bolango sekaligus melaksakan pelatihan penggunaan sistem informasi tersebut. Dengan adanya sistem informasi ini diharapkan dapat meningkatkan kinerja aparat desa dalam rangka pelayanan kepada masyarakat.

Upaya untuk tetap menggunakan sistem informasi pengelolaan surat keluar di Desa Dunggala perlu dipertahankan dengan meningkatkan sistem menjadi online dan melengkapi basis data penduduk. Perlu keseriusan dari pihak desa untuk dapat menggunakan sistem informasi ini guna mempermudah dan mengefektifkan pelayanan terhadap masyarakat.

\section{UCAPAN TERIMA KASIH}

Penulis mengucapkan terimakasih kepada Lembaga Penelitian dan Pengabdian kepada Masyarakat (LPPM) Universitas Negeri Gorontalo yang telah memberikan dukungan selama berlangsungnya Program PKM ini.

\section{DAFTAR PUSTAKA}

[1] Undang-Undang Republik Indonesia Nomor 6 Tahun 2014 tentang Desa.

[2] Undang-Undang Republik Indonesia Nomor 25 Tahun 2009 tentang Pelayanan Publik.

[3] Kadir, A. 2003. Pengenalan Sistem Informasi. Yogyakarta: Penerbit ANDI.

[4] Bahroni, I., Prihantara, A. . 2017. Rancang Bangun Sistem Informasi Administrasi Kependudukan e-Desa Berbasis Web (Studi 
Kasus di Kelurahan Tritih Kulon Cilacap Utara). Jurnal Infotekmesin. 8(1):26-32.

[5] Handayani, P. K. 2016. Sistem Informasi Administrasi Data Kepegawaian Pada Bagian Personalia PT. XYZ. Jurnal Simetris.7(1): 373-378.

https://doi.org/10.24176/simet.v7i1.527

[6] Babin, L. 2007. Beginning Ajax with PHP:from Novice to Professional. New York:Apress. ISBN 978-1590596678.

[7] Ernisse, M. 2006. Build Your Own Ajax Web Applications. Victoria: Site Point Pty, Ltd. ISBN 0-9758419-4-7.

[8] Dako, R.D.R., Ridwan, W. 2015. Penerjemah Teks Dua Arah Bahasa Indonesia-bahasa Gorontalo Berbasis Web Sebagai Upaya
Pemertahanan Bahasa Daerah. Konferensi eIndonesia Initiative XI. 236-239.

[9] Paulson, L. D. 2005. Building rich web applications with Ajax. Computer. 38 (10): 14-17. doi: 10.1109/MC.2005.330.

[10] Noyon, A. D., Abid, Y. Md., Hassan, Md. M., Sharif, Md. H., Deepa, F. N., Rumel, R. I., Haque, R., Nasrin, S., Zaman, M. 2018. A Study of Ajax Template Injection in Web Applications. International Journal of Engineering \& Technology. 7 (3): 123-127. doi: 10.14419/ijet.v7i3.13.16337.

[11] Ullman, C., dan L. Dykes. 2007. Beginning Ajax. Wiley Publishing Inc.

[12] Apache Friends. 2020. What is XAMPP. https://www.apachefriends.org/index.html. Akses September 2020. 
Jati Emas (Jurnal Aplikasi Teknik dan Pengabdian Masyarakat)

Vol. 4 No. 2 Oktober 2020 - e. ISSN: 2550-0821 